\title{
THE 23:19 AFTERSHOCK OF THE 15 OCTOBER 1979 IMPERIAL VALLEY EARTHQUAKE: MORE EVIDENCE FOR AN ASPERITY
}

\author{
By Hsui-Lin LiU* and Donald V. Helmberger
}

\begin{abstract}
The well-recorded strong ground motion data for the 23:19 aftershock of the 15 October 1979 Imperial Valley earthquake provide a good opportunity to study the high-frequency source characteristics and the path effects at near-source distances.

The best-fitting point source model has a strike-slip mechanism, $\mathrm{N} 40^{\circ} \mathrm{W}$, which is nearly identical to the main event. The estimated stress drop is extremely high, roughly 500 bars, with a triangular time history $(0.1,0.1 \mathrm{sec})$ but with a moment of $1.0 \times 10^{24}$ dyne-cm. A double-source model found by inversion fits the highfrequency data better but indicates complex faulting: the first source (with strike $=\mathrm{N} 319^{\circ} \mathrm{E}$, dip $=42^{\circ} \mathrm{NE}$, and slip angle $=165^{\circ}$ ) has a moment of $0.7 \times 10^{24}$ dyne$\mathrm{cm}$, the second source (with strike $=\mathrm{N} 324^{\circ} \mathrm{E}$, dip $=82^{\circ} \mathrm{SW}$, and slip angle $=$ $181^{\circ}$ ) lies about $0.5 \mathrm{~km}$ to the north and has a seismic moment twice that of the first source. Source dimensions appear very small for this amount of energy release. Many of the anomalous behaviors observed at certain stations for the main event are, also, present in the aftershock data. These features are examined in terms of path effects.
\end{abstract}

\section{INTRODUCTION}

In recent years, significant progress has been made in understanding long-period strong ground motions (displacements) produced by some of the larger California earthquakes, Assuming a distributed shear dislocation along planar surfaces embedded in a layered velocity structure provides an adequate set of parameters for modeling observations in a deterministic sense. Unfortunately, such models appear inadequate to explain the higher frequency signals (velocities or accelerations) which apparently are not consistent with the radiation patterns predicted from the longer period studies. What causes this breakdown of the deterministic approach at high frequencies is not clear. Crustal scattering (inappropriate Green's function), microsource complexity (irregular dislocation elements), and perhaps macrosource complexity (interference of waves produced by various portions of the fault) are possible reasons. The latter cause of complexity can be largely eliminated by selecting a small event where the dislocation is confined to a localized region. We propose to study such an event and to address the first two possibilities, namely crustal scattering and irregular source elements. The event modeled in this study is an aftershock of the 15 October 1979 Imperial Valley earthquake, that was very well recorded by the Imperial Valley strong-motion array at all azimuths and at distances ranging from 8 to $26 \mathrm{~km}$. Furthermore, we have the rare opportunity to compare $P$ waveforms with $S$ waveforms which allows the estimation of different apparent attenuation coefficients within the sedimentary basin.

\section{THE 23:19 AFTERSHOCK}

The 15 October $23: 19$ aftershock $\left(M_{L}=5.0\right)$ occurred about $2 \frac{1}{2}$ min after the main shock, and unfortunately most of the far-field data are overwhelmed by the coda of

\footnotetext{
* Present address: Schlumberger-Doll Research, Ridgefield, Connecticut 06877.
} 
the main event. The only available information for this aftershock is from the strong-ground motion recordings. Using these data as well as some low-gain array data, the epicenter was located at $32^{\circ} 46.00^{\prime} \mathrm{N}$ and $115^{\circ} 26.48^{\prime} \mathrm{W}$ and at a depth of $9.5 \mathrm{~km}$ (Brady and Porcella, 1983; Carl Johnson, personal communication, USGS), which is on the Imperial fault near Highway 8 and close to the zone of high energy release for the main shock (Hartzell and Helmberger, 1982).

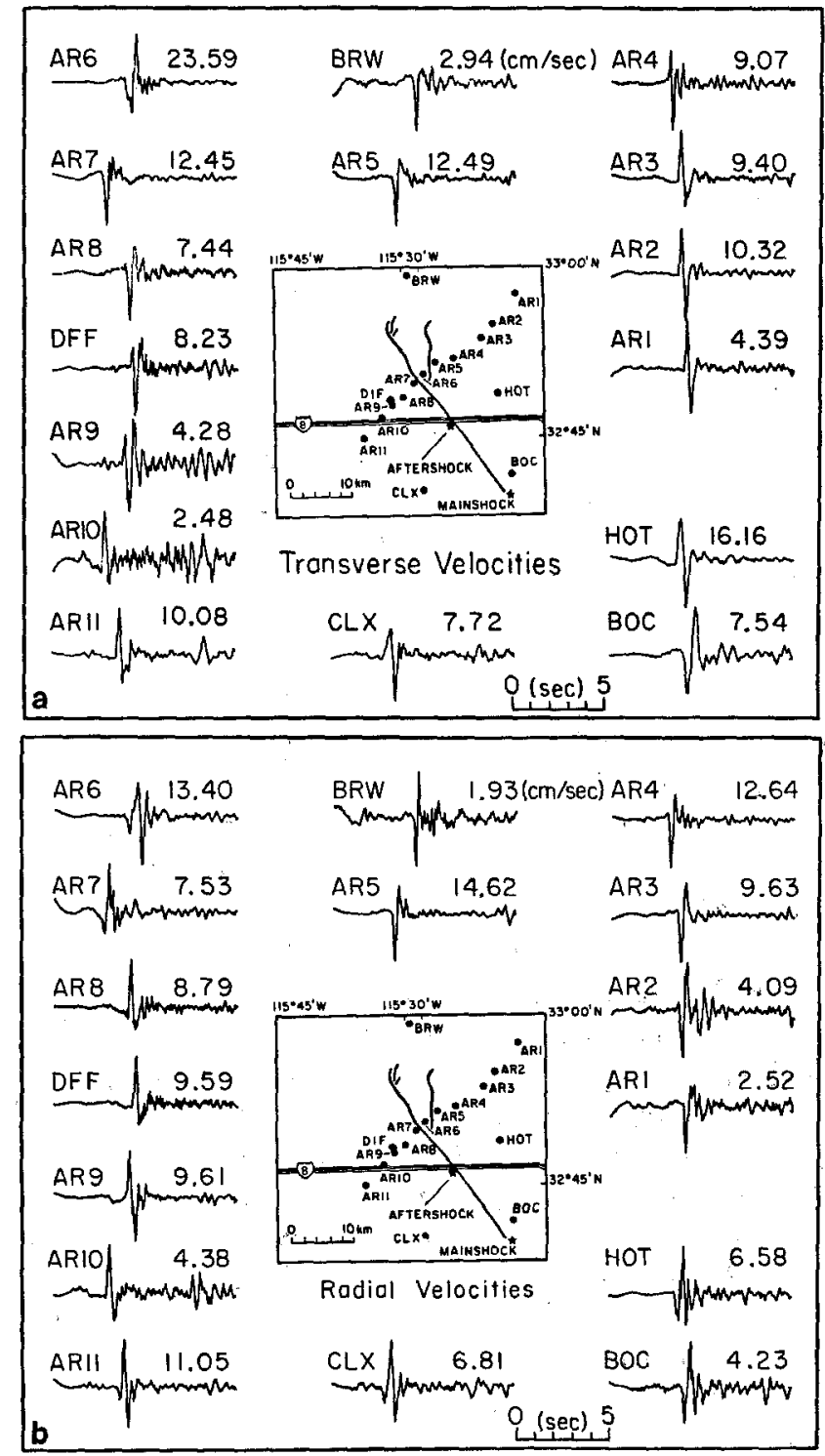

FIG. 1. (a) The transverse of ground velocities from the 23:19, 15 October 1979 Imperial Valley aftershock. (b) The radial of ground velocities from the 23:19, 15 October 1979 Imperial Valley aftershock.

Figure 1, a and b, shows the transverse and radial horizontal ground velocities from 16 array stations. The impulsive waves are the $S$ arrivals, which are the main signals on the horizontal component. The ground accelerations indicate similar impulsive $S$ waves but contain more high-frequency complications. Most of the traces start at the $P$-arrival times, except for the six stations (AR6, AR8, AR9, 
DFF, HOT, and BOC) which were still in the triggered mode from the main event. Due to the rather small $P$-wave amplitude on the horizontal component, we can only identify the $P$ waves by the timing comparison between horizontal and vertical traces. The predominant strike-slip mechanism and the slow velocity structure near the surface produce negligible $P$ waves on the horizontal components, a very common feature observed in most of the Imperial Valley accelerograms (Liu and Helmberger, 1981).

At most stations, the first $S$-wave particle motion is consistent with a rightlateral strike-slip motion, with the strike nearly parallel to the Imperial fault, $\mathrm{N} 40^{\circ} \mathrm{W}$. The fault plane solution ( strike $=\mathrm{N} 40^{\circ} \mathrm{W}$, dip $=90^{\circ}$, and rake $=180^{\circ}$ ) satisfies most of the $S$-wave motions except those near the $S$-wave nodal directions.

There is an indication of directivity observed on the variation of signal durations at different azimuths, (Figure 2). In order to avoid the possible converted phases, the time duration is the velocity pulse width (in seconds) measured on the transverse component. For near $S H$-node stations, we use the average time duration measured from both components. Except for station 6, all the other array stations show time

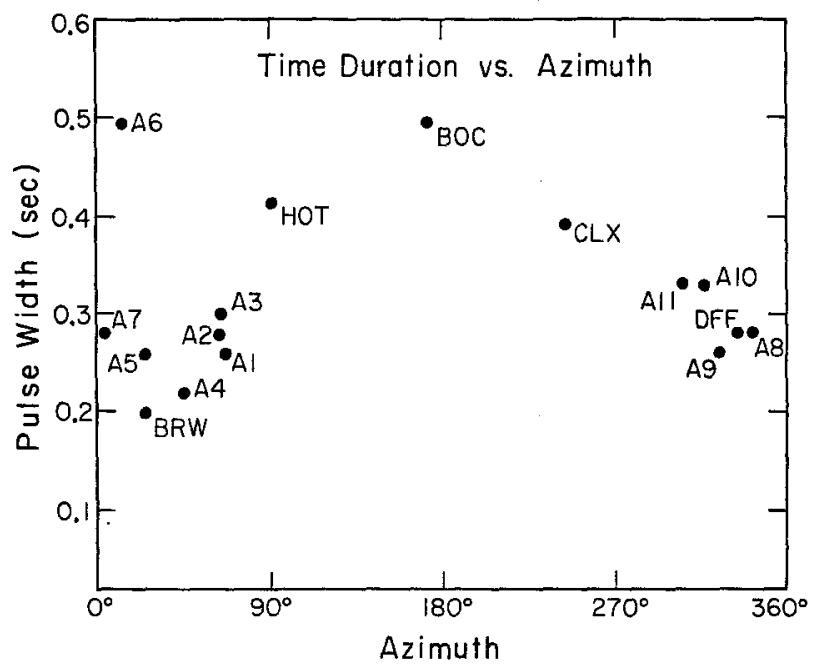

FIG. 2. Time duration of the $S H$ velocity pulse width versus station azimuth. The azimuth is measured from the fault strike $\left(\mathrm{N} 40^{\circ} \mathrm{W}\right)$ clockwise to the station.

durations consistent with a northward faulting process. We can roughly estimate the fault length by using the difference in time duration of $S$ waves between station AR5 $(0.25 \mathrm{sec})$ and station BOC $(0.5 \mathrm{sec})$, which are located NW and SE along the strike direction, respectively. Assuming a rupture velocity of $3 \mathrm{~km} / \mathrm{sec}$ toward the north, the fault length is estimated to be about $1.1 \mathrm{~km}$. If we use the sum and differences of the extreme durations, we obtain estimates of fault length, less than $0.5 \mathrm{~km}$, and rupture velocity, less than $1 \mathrm{~km} / \mathrm{sec}$. These values of fault dimensions, especially the latter, are unusually small for an event of this magnitude and will be discussed at length later.

The ground motions on vertical components are much smaller in amplitude and more incoherent in waveform. Only six stations (AR6, AR8, AR9, DFF, HOT, and BOC) show complete $P$ arrivals on the velocity traces, because only these six stations continued recording after the triggering for the main event. These vertical ground motions are valuable in quantifying the difference between $P$ and $S$ waves propagating within a sedimentary basin. 


\section{FORWARD MODELING}

Forward modeling of the horizontal velocities using a point source solution with a pure strike-slip mechanism is first presented to illustrate the general nature of the observed ground motions. The disagreement between the data and this single point source solution at near-node stations leads us to consider a more complex source hypothesis.

The velocity structure used to calculate the Green's function is listed in Table 1, which was obtained from Fuis et al. (1981) and modified by Liu and Helmberger (1981). The generalized ray method (Helmberger and Harkrider, 1978) is used to calculate the response. The time interval used in computing is $0.005 \mathrm{sec}$. Because the source depth is large relative to the distance from epicenter to station, we

TABLE 1

VELOCITY STRUCTURE

\begin{tabular}{rcccc}
\hline & Thickness $(\mathrm{km})$ & $\alpha(\mathrm{km} / \mathrm{sec})$ & $\beta(\mathrm{km} / \mathrm{sec})$ & $\rho\left(\mathrm{gm} / \mathrm{cm}^{3}\right)$ \\
\hline 1 & 0.105 & 1.69 & 0.35 & 1.52 \\
2 & 0.105 & 1.70 & 0.40 & 1.53 \\
3 & 0.105 & 1.72 & 0.50 & 1.56 \\
4 & 0.105 & 1.79 & 0.60 & 1.61 \\
5 & 0.105 & 1.93 & 0.70 & 1.74 \\
6 & 0.105 & 2.05 & 0.80 & 1.85 \\
7 & 0.105 & 2.10 & 0.90 & 1.89 \\
8 & 0.105 & 2.15 & 1.00 & 1.94 \\
9 & 0.105 & 2.25 & 1.15 & 2.03 \\
10 & 0.105 & 2.38 & 1.30 & 2.15 \\
11 & 0.339 & 2.50 & 1.50 & 2.26 \\
12 & 0.480 & 2.67 & 1.64 & 2.36 \\
13 & 0.160 & 2.85 & 1.74 & 2.39 \\
14 & 0.160 & 3.15 & 1.91 & 2.44 \\
15 & 0.160 & 3.45 & 2.08 & 2.48 \\
16 & 0.160 & 3.57 & 2.15 & 2.50 \\
17 & 0.640 & 3.70 & 2.22 & 2.52 \\
18 & 0.160 & 3.85 & 2.30 & 2.55 \\
19 & 0.160 & 4.20 & 2.50 & 2.60 \\
20 & 0.160 & 4.55 & 2.71 & 2.63 \\
21 & 2.271 & 4.70 & 2.75 & 2.65 \\
22 & 5.0 & 5.50 & 3.40 & 2.75 \\
23 & 10.0 & 7.20 & 4.10 & 2.80 \\
\hline
\end{tabular}

include only direct rays of $P, S H$, and $S V$ waves in the calculation. Table 2 lists the epicentral distances for all the recording sites and the observed and the calculated $P$ and $S$ - $P$ times. The velocity model produces good agreement between the observed and calculated $P$ and $S-P$ times for most of the stations within $15 \mathrm{~km}$ of the epicenter.

The short $S-P$ time and small amplitude observed at station AR10 suggest that there exists some local high-velocity structure which reduces the $S$ travel time. The recordings in station AR6 are unusual in many aspects. The $S H$ arrival at station AR6 is 0.55 sec. later than that at station AR7, yet the epicentral range differs by only $0.3 \mathrm{~km}$.

At more distant stations, AR1, AR2, and BRW, the observed $S-P$ times are shorter than calculated. This is in agreement with the suggestion by Fuis et al. (1981) that sediments are thinning toward these stations. 
One-source model. Synthetic velocity traces for a single vertical strike-slip point source model $\left(\mathrm{N} 40^{\circ} \mathrm{W}\right)$ and the observed data are shown in Figure 3, a and b, for the transverse and radial components, respectively. A triangular time function $(0.1$ $\mathrm{sec}, 0.1 \mathrm{sec}$ ) is used to represent the far-field source time function. The numbers indicate amplitude ratios of the data to the synthetics for a seismic moment of 1.0 $\times 10^{24}$ dyne-cm. The radiation pattern shows the synthetic amplitude normalized by the rms of the transverse and the radial amplitudes. The waveforms agree

TABLE 2

Epicentral Distances and Travel Times

\begin{tabular}{lrrrrr}
\hline Station & $\begin{array}{c}\text { Distance } \\
(\mathrm{km})\end{array}$ & $\begin{array}{c}\text { Observed- } P \\
(\mathrm{sec})\end{array}$ & $\begin{array}{c}\text { Thickness-P } \\
(\mathrm{sec})\end{array}$ & $\begin{array}{c}\text { Observed } S-P \\
(\mathrm{sec})\end{array}$ & $\begin{array}{c}\text { Thickness } S-P \\
(\mathrm{sec})\end{array}$ \\
\hline AR1 & 24.3 & 5.78 & 5.872 & 4.0 & 4.466 \\
AR2 & 18.3 & 4.88 & 4.809 & 3.65 & 3.855 \\
AR3 & 14.8 & 4.28 & 4.203 & 3.5 & 3.475 \\
AR4 & 10.4 & 3.50 & 3.478 & 3.05 & 3.016 \\
AR5 & 10.7 & 3.48 & 3.525 & 3.0 & 3.046 \\
AR6 & 9.2 & 3.38 & 3.294 & 3.1 & 2.897 \\
AR7 & 8.9 & & & 2.55 & 2.868 \\
AR8 & 9.6 & & & 2.8 & 2.936 \\
AR9 & 10.5 & & & 2.9 & 3.025 \\
AR10 & 12.1 & & & 2.7 & 3.189 \\
AR11 & 14.1 & & & 3.5 & 3.401 \\
DFF & 10.0 & & & 2.8 & 2.975 \\
HOT & 7.5 & & & 2.8 & 2.739 \\
CLX & 11.6 & 4.09 & 3.669 & 3.0 & 3.138 \\
BOC & 12.7 & 3.88 & 3.862 & 3.2 & 3.259 \\
BRW & 25.6 & 5.84 & 6.105 & 4.3 & 4.659 \\
\hline
\end{tabular}
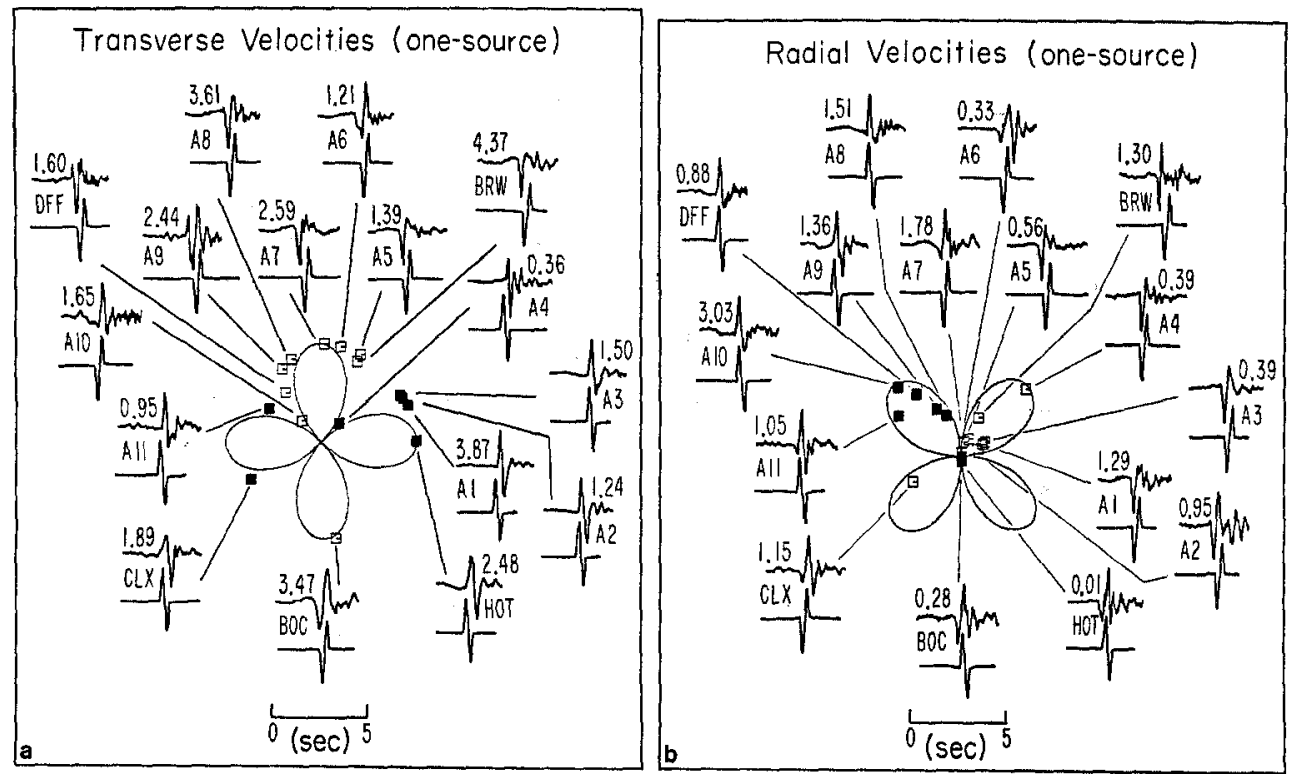

FIG. 3. (a) Waveform comparisons of the transverse ground velocities versus synthetics. The synthetic velocities are computed from a pure right-lateral strike-slip point source along $\mathrm{N} 40^{\circ} \mathrm{W}$. The total moment is $1.0 \times 10^{24}$ dyne-cm. A triangular source time function of $(0.1 \mathrm{sec}, 0.1 \mathrm{sec})$ was used in this calculation. The numbers are the amplitude ratios of the data to the synthetics. The four-lobed radiation pattern is also plotted from the normalized synthetic amplitudes. (b) Waveform comparisons of the radial ground velocities versus synthetics. The source mechanism is the same as that in (a). 
reasonably well between the data and the synthetics, although the amplitudes are not well matched at all stations.

Figure 4 illustrates an example of ground motions near an $\mathrm{SH}$ node. By examining the horizontal recordings at stations AR3, AR4, and AR5, the polarity reversal in the transverse components suggests that the $S H$ node for this aftershock passes somewhere between array stations AR4 and AR5, but closer to AR4. However, in terms of amplitude, it is difficult to recognize that station AR4 is near an $S H$ node, especially if accelerations are considered. In station AR4, the amplitude ratio of the transverse to the radial component is 0.7 in displacement and about 1.2 in acceler-

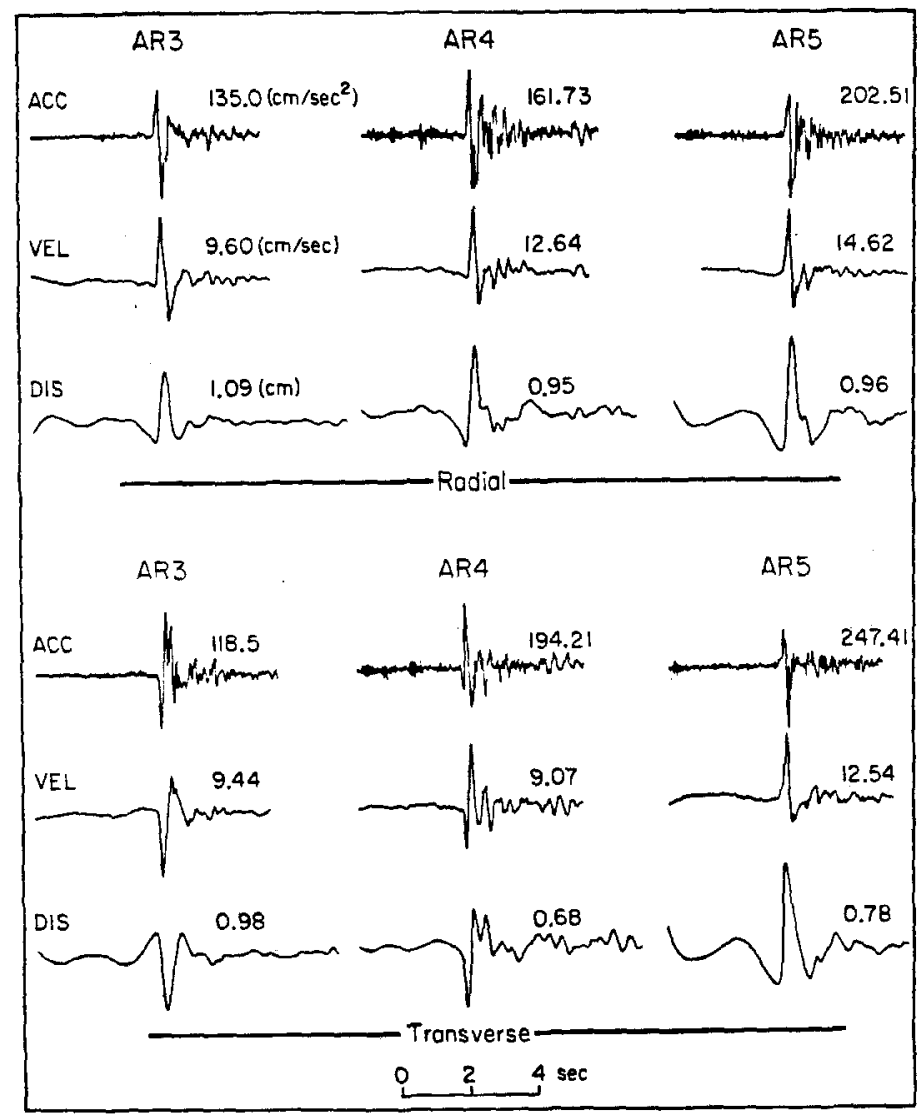

FIG. 4. The horizontal accelerations, velocities and displacements at array stations AR3, AR4, and AR5. The $S H$ node is near station AR4.

ation. Thus, a single source model which has sharp nodes explains the longer period ground motions better than at the shorter periods. Similar features can be observed at most of the other near-node stations, such as the transverse components of DFF and AR9 and the radial components of BOC, HOT, AR6, and AR7. For wavelengths less than the fault size of this aftershock (about $1 \mathrm{~km}$ ), we expect to see a more complex rupture mechanism, which can perhaps smear out the nodes. This corresponds to a period of about $0.3 \mathrm{sec}$. Thus for wave periods less than $0.3 \mathrm{sec}$, the effects of source irregularities are expected to become more important.

Two-source model. For simplicity, we simulate a nonsmooth rupture process by superimposing two point sources rupturing one after the other with a given time 
delay. The effect of such a complex source on the radiation pattern is described next.

Through a trial and error test, we found that an extra point source with a different fault geometry can be added to improve the amplitude ratio at near nodal stations. In Figure 5, we show the waveform comparisons for horizontal velocities at station AR4 for the two point source solution with a time delay between the sources of 0.1 sec. As indicated in Figure 5, a variation in the source orientation along the rupture plane can easily smear out the nodes and improve the amplitude ratio between the two components. However, this approach will increase the source parameters rapidly, and the forward modeling method becomes cumbersome to manage. In order to find a complex source mechanism appropriate for all stations, we introduce an amplitude inversion scheme which allows the source orientation to vary freely

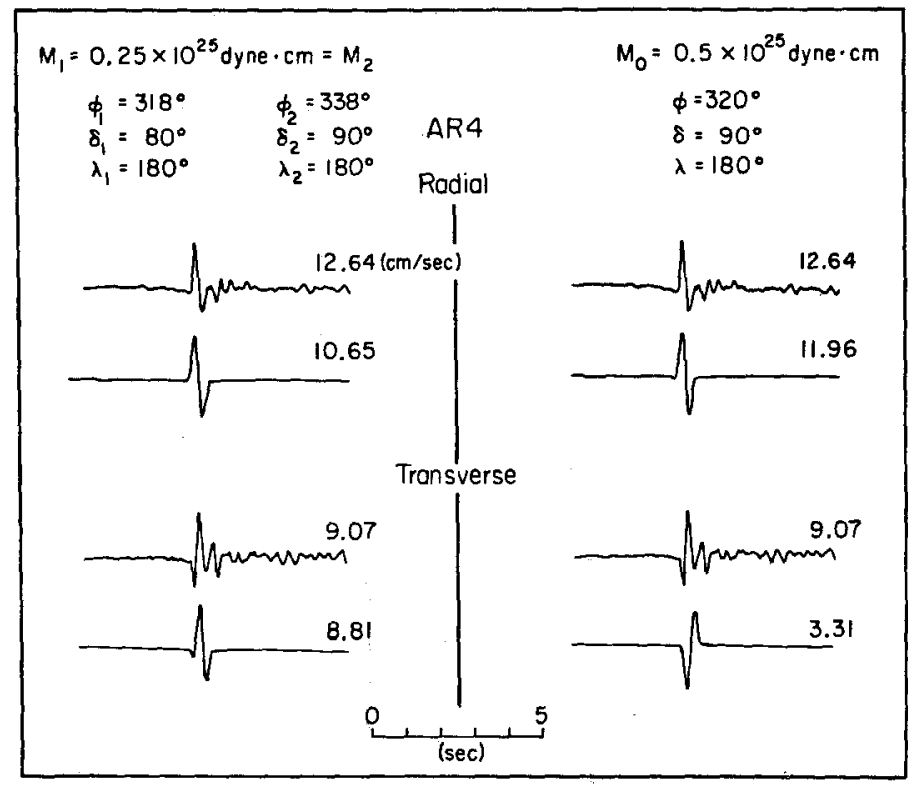

FIG. 5. Comparisons of data versus synthetics for station AR4. In the right column, the synthetics are computed from a single point source model, which can account for about 30 per cent of the amplitude on the transverse component. The left column shows the synthetics computed for a complex two-source solution, which can produce amplitudes comparable to the observations in both components.

and gives an optimal solution by minimizing the integrated amplitude difference between the data and the synthetics.

\section{INVERSION METHOD}

In order to include the amplitude information in the inversion procedure, we define an error function $e_{i}$ for each seismogram $i$, as

$$
e_{i}=\int_{0}^{T}\left[f_{i}(t)-g_{i}(t)\right]^{2} d t
$$

where $f_{i}(t)$ represents the observed data trace, $g_{i}(t)$ is the synthetic seismogram generated from starting model parameters, and $T$ is the time segment used in the inversion procedure which is similar to the waveform inversion method used by Wallace et al. (1981) and Mellman (1978), except that this inversion scheme includes 
amplitude information, see Appendix for details. The optimal solution is obtained through an iterative least-squares procedure which minimizes the sum of the squares of the error functions.

The source parameters include the seismic moment, strike direction, rake, and dip for each source element. The model variation, $\varphi$, can easily be obtained from $A$, the matrix of partials constructed from the derivatives of the error function with respect to the model parameters, and the error function, $e$, by applying the following relationship

$$
\varphi=\left(A^{T} A\right)^{-1} A^{T} e,
$$

where -1 represents the inverse and the superscript $T$ denotes the transpose.

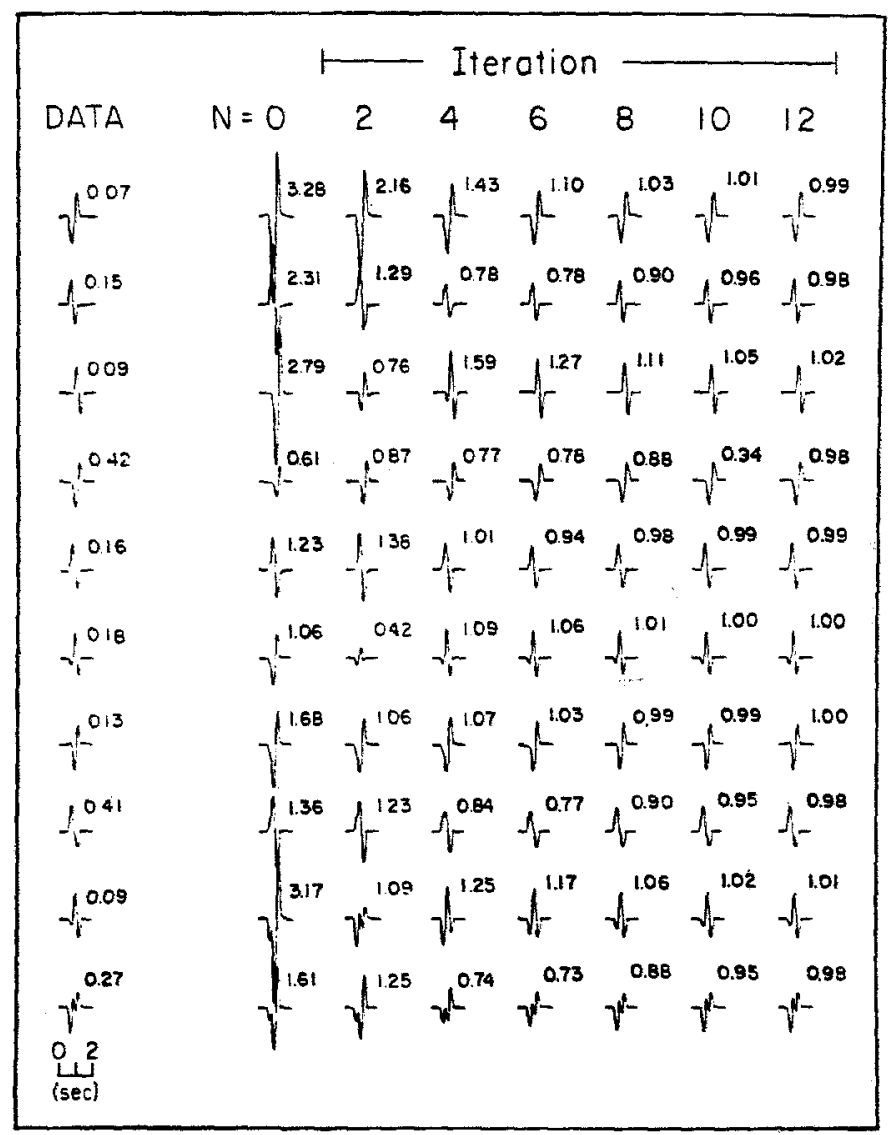

FIG. 6. The amplitude inversion procedure. The data consist of two equal seismic moment sources. The absolute amplitudes for the synthetic data are also indicated. By using the dampling coefficient of 0.05 , we can reach reasonable solution after eight iterations. The number associated with each seismogram in iteration procedure is the amplitude ratio of the synthetic to the data.

Using the displacement expressions in cylindrical coordinates (Helmberger and Harkrider, 1978), the error function can easily be calculated by the linear sum of the auto- and cross-correlations of the data and the Green's functions with coefficients dependent on source orientations. For each iterative inversion step, we need to evaluate the error function and partials, but the correlation functions need to be estimated only once.

Figure 6 shows an example of the inversion procedure. The synthetic data consist 
of two point sources; the first one has strike $=\mathrm{N} 318^{\circ} \mathrm{E}, \operatorname{dip}=80^{\circ} \mathrm{NE}$, and rake $=$ $180^{\circ}$, and the second source has strike $=\mathrm{N} 338^{\circ} \mathrm{E}$, dip $=90^{\circ}$, and rake $=180^{\circ}$. Both sources have the same seismic moments. We assign a time delay between these two sources prior to the inversion procedure for each data trace, based on a trial and error test. The data are weighted so that all the observed peak amplitudes are normalized to unity. This can reduce the unknown local amplification effects. A damping coefficient of 0.05 is used to stabilize the inversion procedure (see Appendix). The initial model $(N=0)$ shown in Figure 6 assumes two sources with the same fault orientations: strike $=\mathrm{N} 300^{\circ} \mathrm{E}, \operatorname{dip}=60 \mathrm{NE}$, and rake $=150^{\circ}$. The initial seismic moment for the second source is four times larger than the first source. The parameters which are allowed to vary in the inversion procedure are strike, dip, rake, and seismic moment for each source element. As illustrated in Figure 6, after eight iterations, a solution is found that matches the data very well.

\section{ApPlication to Modeling the ObSERved Velocities}

The starting model for the inversion consists of two sources with parameters nearly the same as in the one-source case; namely

source 1: strike $=\mathrm{N} 318^{\circ} \mathrm{E}$, dip $=80^{\circ} \mathrm{NE}$, rake $=180^{\circ}$ source 2: strike $=\mathrm{N} 338^{\circ} \mathrm{E}, \operatorname{dip}=90^{\circ} \mathrm{NE}$, rake $=180^{\circ}$

These sources have the same time histories as before and are assigned equal moment. Time delays between the two sources were assigned from the directivity plot discussed earlier (Figure 2). These delays are (0.1) for all stations except AR5 and BRW which are (0.05) and HOT, CLX, and BOC with values of (0.2). Station AR6 was not included because of the possible site effects which will be discussed later. AR2 and AR1 were also rejected because of the large difference between their $S-P$ times relative to the velocity model (Table 2). BRW is at a large enough distance to be affected by diving ray paths. These down-going paths could effect the wave shape in an unknown manner and it was removed. However, as we will see shortly, these stations are modeled about as well as the others.

The observed seismograms are each weighted by the inverse of the peak amplitude to increase the sensitivity of the inversion process to the waveform observed at low amplitude seismograms. Allowing the inversion code to vary the orientation angles and moments yield the results presented in Figure 7 , $a$ and $b$. The radiation pattern shows the synthetic amplitude normalized by the rms of the transverse and the radial amplitudes. We also show comparisons of observed data versus synthetics for stations AR1, AR2, BRW, and AR6, which were not used in the inversion procedure. Since we normalize the data to unit peak amplitude, high amplitude data do not dominate the inversion solution, and the waveform of small amplitude data is well restored.

Although the inversion solution is chosen based on the minimum error criteria, two-thirds of the seismic moment (the second source) is consistent with a nearly pure strike-slip motion, which is close to the single source mechanism. This inversion solution provides a better waveform match in the transverse components ( $S H$ waves), and it, also, smears the radiation nodes as indicated in the observation (Figure 7a). The radial components seem to have more discrepancies between the data and the synthetics. One possible reason is that the $P$ and $S V$ converted phases are not well modeled by our assumed structure.

We also show comparison of six vertical velocities versus synthetics from this 
inversion solution in Figure 8. For stations AR8, AR9, and DFF, which are near the maximum of $P$ or $S V$ waves, the synthetics match the data reasonably well in waveform and amplitude.

\section{Ground ACCEleration and AtTEnuation}

We use the inversion solution obtained from velocity data to generate synthetic accelerograms for the 16 recording sites. Comparisons of data and synthetics are shown in Figure 9, a and b, for the transverse and radial components, respectively. The amplitude ratios of the data to the synthetics are also indicated. An extratriangular function $(0.05 \mathrm{sec}, 0.05 \mathrm{sec})$ is convolved with the seismograms to reduce the noise due to the time derivative. Although there is more high-frequency complexity
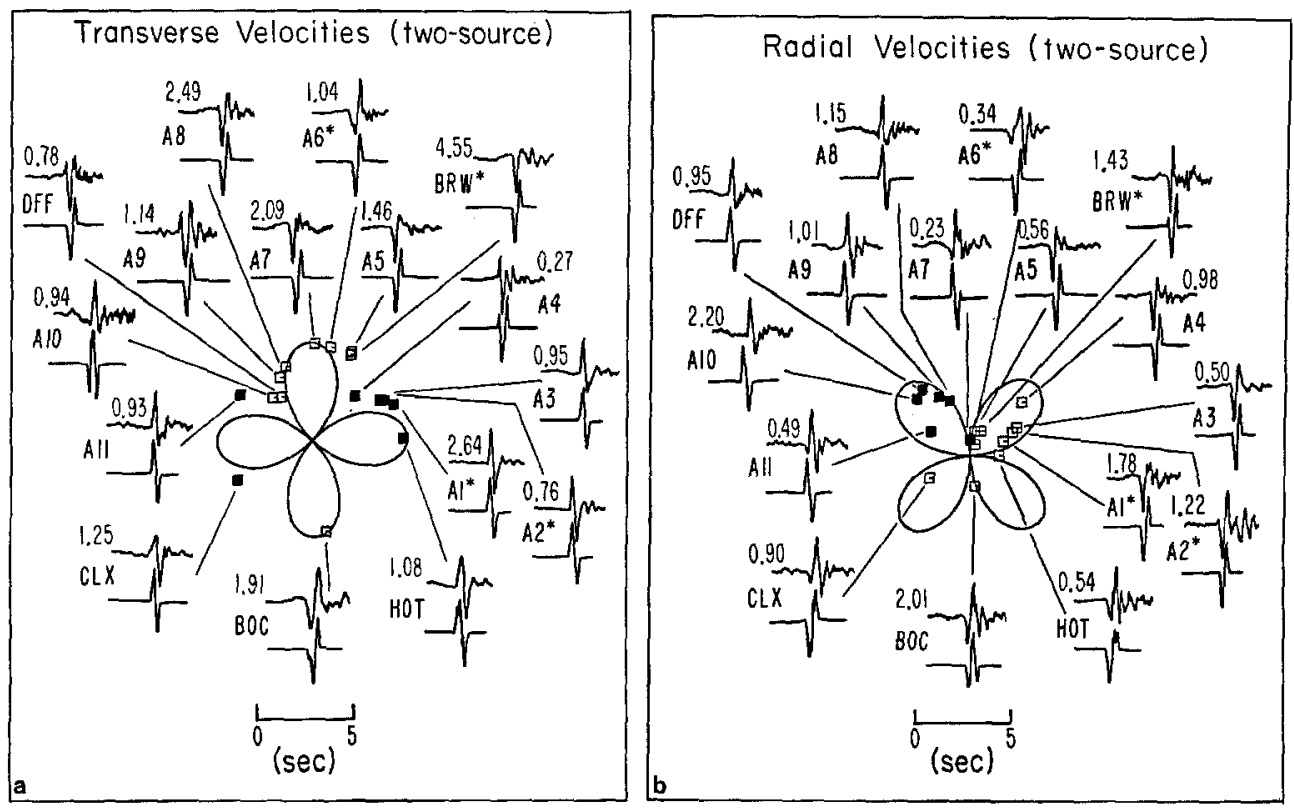

FIG. 7. (a) Comparisons of the synthetics from inversion method versus the data for the transverse ground velocities. The numbers are amplitude ratios of the data to the synthetics. The inversion solution contains two sources: the first source has a seismic moment of $0.7 \times 10^{24}$ dyne-cm and has strike $=$ $\mathrm{N} 319^{\circ} \mathrm{E}$, dip $=42^{\circ} \mathrm{NE}$, and rake $=165^{\circ}$; the second source has twice the first seismic moment and has strike $=\mathrm{N} 324^{\circ} \mathrm{E}$, dip $=82^{\circ} \mathrm{SW}$, and rake $=181^{\circ}$. (b) Comparisons of the synthetics from inversion result versus the data for the radial ground velocities.

in the data, the synthetic waveforms generally match the beginning $1-\mathrm{sec}$ of the data quite well. Due to the possible conversion phases, the radial components have more high-frequency complications than the transverse components, as seen in stations BOC, HOT, AR7, AR6, and AR2.

The $P$-wave accelerations tend to be a much higher frequency than the $S$-wave accelerations as displayed in Figure 10. This feature is commonly observed in recordings of events in the Imperial Valley and basins in general. When these records are integrated to produce velocities or displacements the differences tend to disappear. This apparent difference in time histories or corner frequencies has been called the corner frequency shift and has been noted many times, see, e.g., Hanks (1981). Such features can be explained to some degree by dynamic models considerably more complicated than the Haskell dislocation type assumed in this study (Molnar et al., 1973). 
An alternative explanation for the corner frequency shifts as reported in the literature can in many situations be explained in terms of propagational complexities. For instance, in this particular case we will consider the differential properties of absorption on $P$ and $S$ waves as the cause.

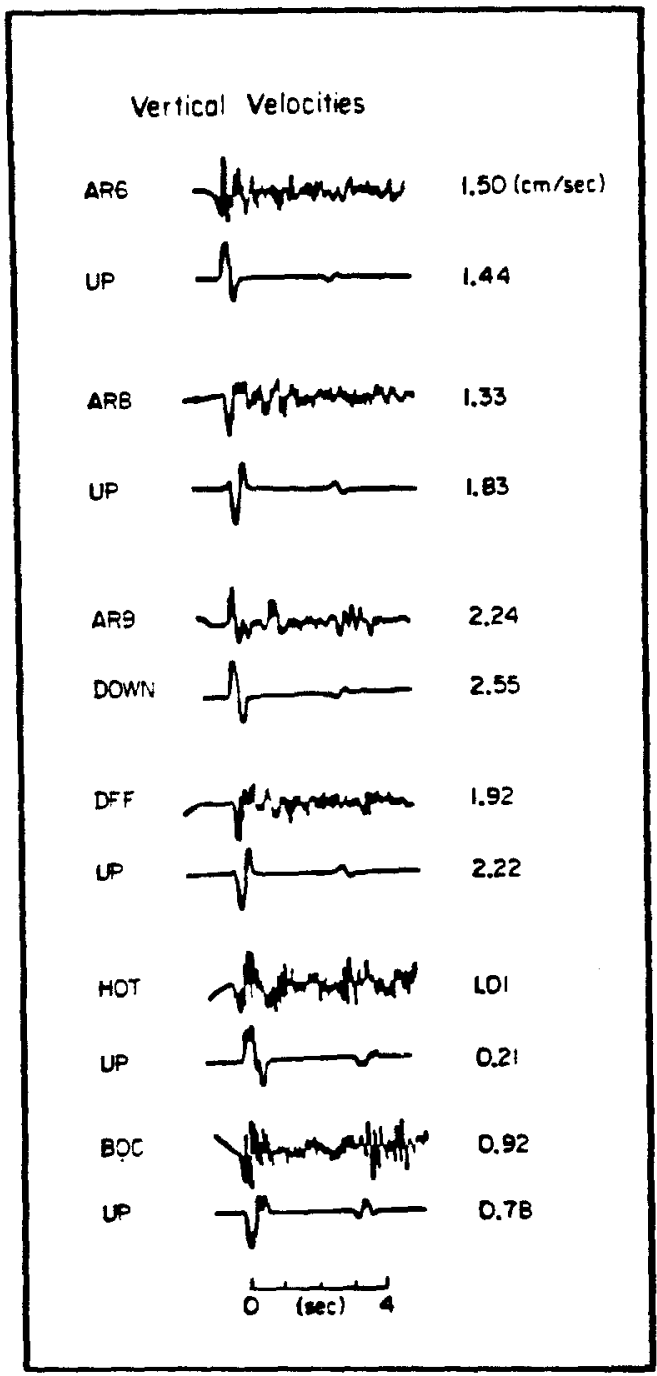

FIG. 8. Comparisons of vertical velocities versus synthetics. The synthetic seismograms are computed from the inversion solution derived from horizontal velocities.

The attenuation of body waves which travel some specified path with a $Q$ distribution can be parameterized by the quantity $t^{*}$,

$$
t^{*}=\sum_{\text {raypath }} d t / Q=T / Q_{A V}
$$

where $T$ is the total travel time of the ray, $\left(t^{*}\right)$ is usually given a subscript $\alpha$ for $P$ waves and $\beta$ for $S$ waves. Thus, a given body wave pulse propagated by an elastic process can be corrected for attenuation by a convolution with the Futterman operator, $F\left(t^{*}, t\right)$ (Carpenter, 1967). 
Examples of $F\left(t^{*}, t\right)$ for various values of $t_{\beta}{ }^{*}$ are displayed in Figure 11. Values of $Q_{\alpha}$ of about 500 have been reported by Helmberger et al. (1979) who studied the behavior of multi-bounce $P$ waves trapped between the ocean surface and the
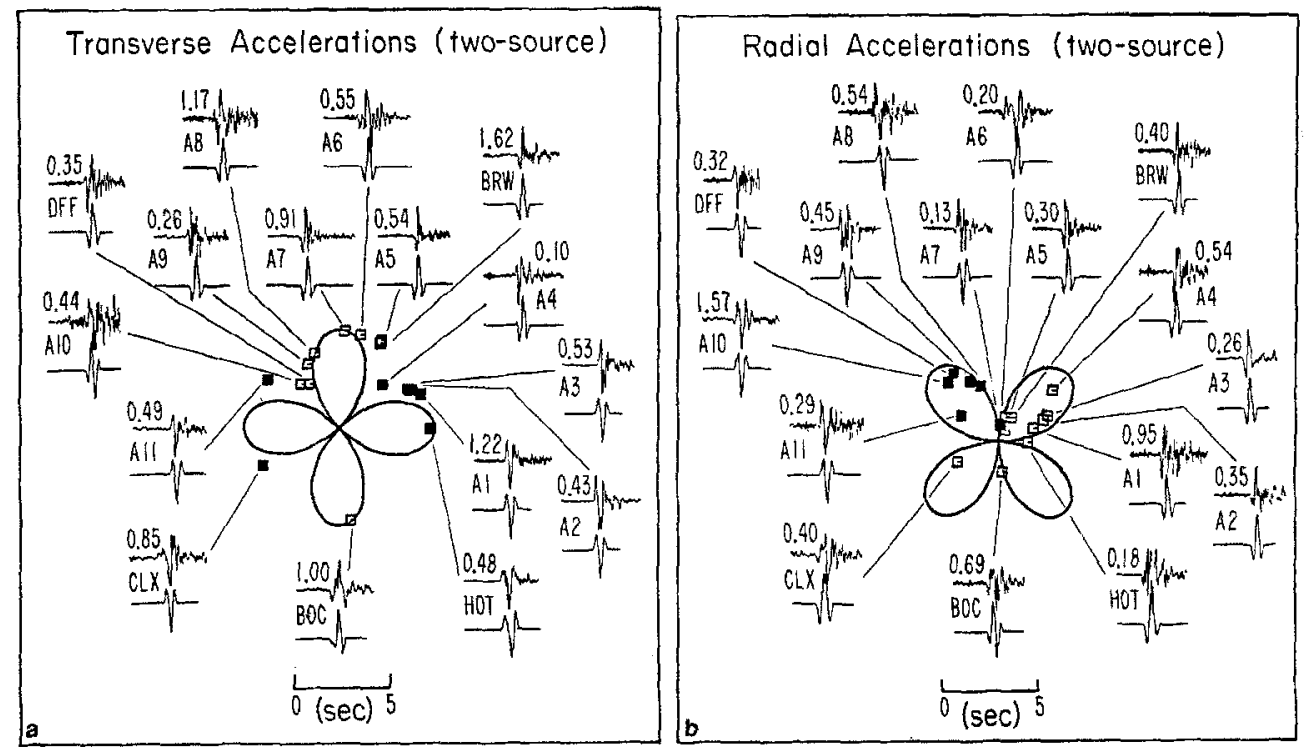

FIG. 9. (a) Comparisons of the transverse ground accelerations versus the synthetics. The synthetic seismograms are computed from the inversion solution derived from velocities. The numbers are amplitude ratios of the data to the synthetics. (b) Comparisons of the radial ground accelerations versus the synthetics.

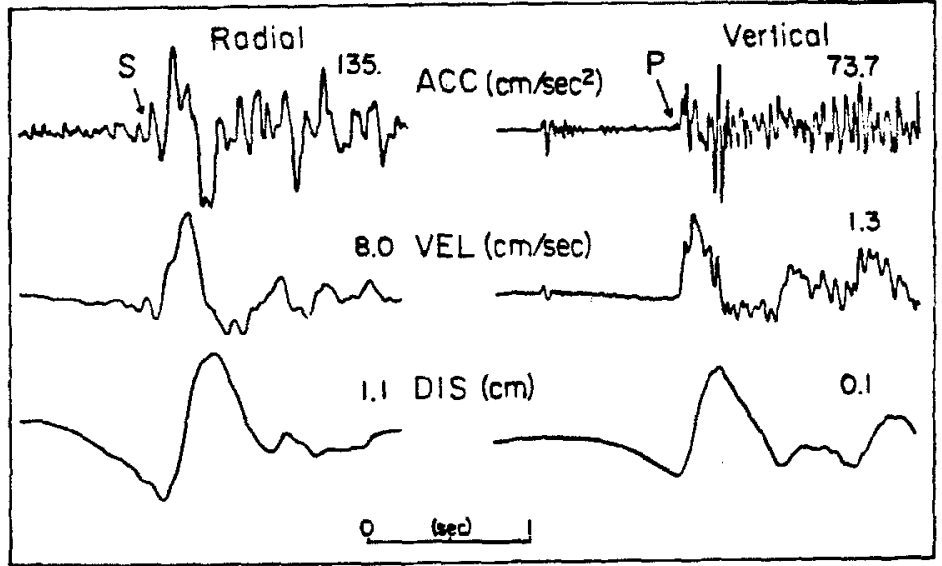

FIG. 10. The radial and vertical ground motions recorded at station AR8.

bottom of the sedimentary column. Estimates of the corresponding $Q_{\beta}$ 's can be obtained by supposing that

$$
Q_{\beta}=\frac{4}{3} \frac{\beta^{2}}{\alpha^{2}} Q_{\alpha}=25
$$

after Anderson et al. (1965) for the structure near the surface. Assuming that the upper kilometer of the basin has this range of values leads to $t_{\beta}{ }^{*} \approx 0.1$ and $t_{\alpha}{ }^{*}=$ 
0.001 . To correct the data for these estimates of attenuation, we could perform the convolution of $t_{\alpha}{ }^{*}$ operator with the $S$ wave and the $t_{\beta}{ }^{*}$ operator with the $P$ waves. But, since the $t_{\alpha}{ }^{*}$ operator is nearly a delta function, we can simply compare the $S$ waves with the filtered $P$ waves. It appears that values of $t_{\beta}{ }^{*}=0.05$ to 0.08 provide reasonable frequency compatability. Thus, it seems that differential attenuation can explain the difference in frequency content with reasonable estimates of $Q$ but this explanation is certainly not definitive.

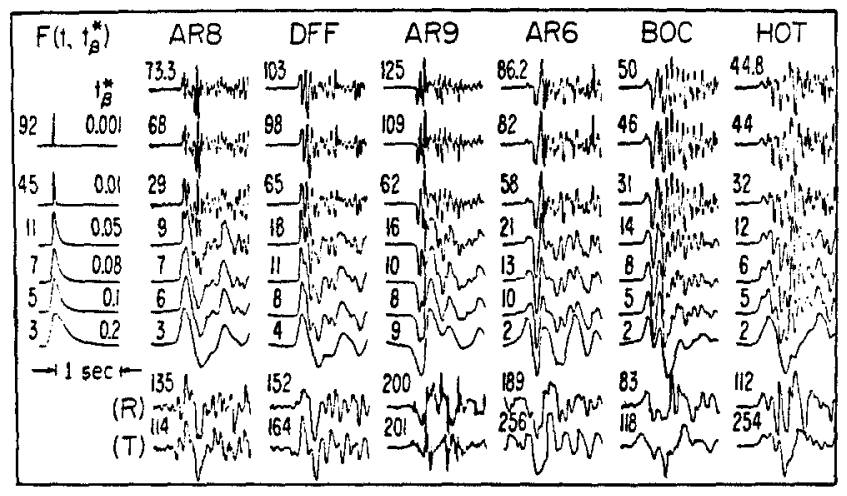

Fig. 11. Comparisons of the resulting vertical seismograms after convolving the Futterman $Q$ operators. The top traces are vertical accelerograms ( $P$ waves) recorded from stations AR6, AR8, AR9, DFF, HOT, and BOC. The bottom two traces are the recorded horizontal accelerations ( $S$ waves). The numbers are the amplitudes.

\section{Discussion AND ConCLUSIONS}

In this section, we will address the amplitude attenuation properties of the peak ground acceleration data as conventionally treated in the engineering community. As shown in Figure 12, this analysis includes the ground accelerations and filtered accelerations centered near $0.5 \mathrm{sec}$ and $1.0 \mathrm{sec}$. We chose the filters such that the frequency contents are close to the ground velocity and displacement, respectively. A list of the filtered data is given in Table 3 . By examining these amplitude-distance plots in light of the modeling results, we will attempt to explain the large scatter seen in the peak ground acceleration data in terms of the known source and propagational features, namely, site effects, directivity, and radiation patterns.

First, note that the amplitude appear to decay by about a factor of two going from 8 to $18 \mathrm{~km}$ which is about the rate found in other studies, e.g., see Hadley et al. (1982). From these plots we observe that the most anomalous station appears to be AR6 which has an especially large amplitude at longer periods. The $S$ wave apparently arrives late at this station as indicated in Table 2. On the other hand, we note that the accelerations recorded at station AR10 are smaller than the average at all frequencies and its $S$-wave arrival is earlier than normal travel time. Amplitudes for the main event are also low at this particular station, which suggests that these effects are caused by receiver structure.

The receiver effects at station AR6 seem to be the most peculiar as noted by several investigations [Mueller and Boore (1981) and others]. Some of its characteristics can be obtained by comparing its response with its closest neighbors (Figure 1a). From the above analysis, we know that AR6 is located near the center of the $\mathrm{SH}$ loop, or the maximum of the radiation pattern. Note that AR7, AR5, and BRW have very similar shapes compared to AR6. It appears that the AR6 observation 
starts down as expected but has a large up pulse arriving a few tenths of a second later. This feature can be quantified by hypothesizing a receiver structure complication, $R(t)$, that maps a simple response like AR5 into AR6. An example of such a $R_{\beta}(t)$ is displayed in Figure 13. Also, included in the left-hand corner is a synthetic

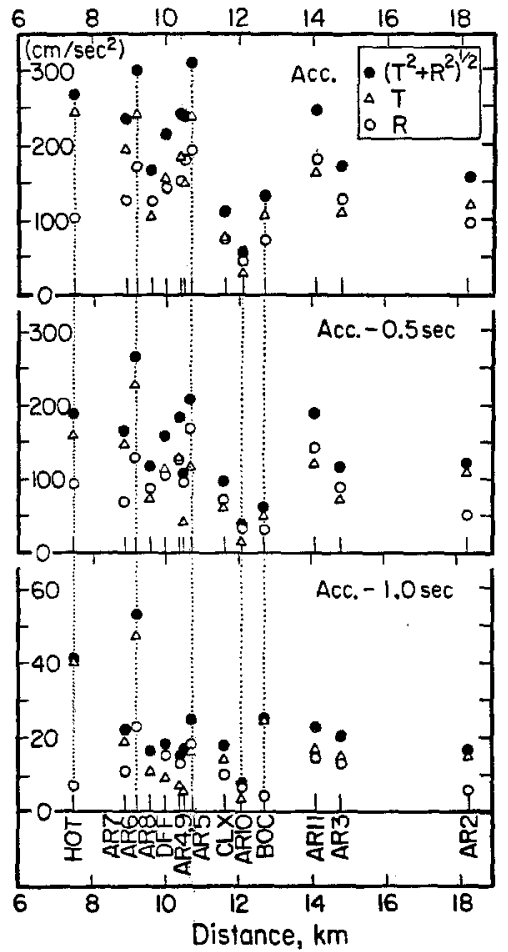

FIG. 12. Amplitude versus distance plots for ground accelerations and filtered accelerations (bandpassed filters centered near $0.5 \mathrm{sec}$ and $1.0 \mathrm{sec}$ ). The data are listed in Table 3.

TABLE 3

PEAK AMPLitudes*

\begin{tabular}{lrrrrrr}
\hline Station & Acceleration $(R)$ & Acceleration $(T)$ & $0.5 \sec (R)$ & $0.5 \sec (T)$ & $1 \mathrm{sec}(R)$ & $1 \mathrm{sec}(T)$ \\
\hline AR1 & 35.28 & 66.79 & 20.80 & 57.96 & 4.59 & 8.10 \\
AR2 & 104.27 & 127.69 & 57.69 & 115.42 & 7.48 & 16.75 \\
AR3 & 136.15 & 118.29 & 96.65 & 79.80 & 14.59 & 16.45 \\
AR4 & 161.13 & 193.43 & 136.77 & 138.43 & 14.44 & 8.26 \\
AR5 & 202.38 & 247.24 & 178.80 & 125.81 & 19.55 & 17.41 \\
AR6 & 180.90 & 251.04 & 140.12 & 238.47 & 24.28 & 48.77 \\
AR7 & 135.88 & 203.28 & 79.80 & 158.34 & 12.39 & 20.09 \\
AR8 & 134.29 & 113.65 & 97.57 & 82.54 & 12.88 & 12.24 \\
AR9 & 189.78 & 158.05 & 106.40 & 51.04 & 17.10 & 6.94 \\
AR10 & 54.11 & 37.57 & 41.91 & 23.59 & 8.17 & 4.94 \\
AR11 & 188.68 & 170.42 & 150.41 & 128.00 & 16.08 & 18.36 \\
DFF & 152.35 & 164.38 & 116.12 & 124.16 & 16.74 & 10.62 \\
HOT & 112.52 & 253.95 & 104.50 & 170.48 & 8.46 & 41.47 \\
BOC & 81.97 & 115.02 & 39.69 & 58.54 & 5.86 & 26.02 \\
CLX & 84.03 & 86.43 & 81.49 & 69.70 & 11.56 & 15.48 \\
BRW & 49.08 & 59.35 & 30.80 & 29.83 & 1.77 & 4.39 \\
\hline
\end{tabular}

* The filter used for the 0.5-sec window has a high-cut at $5 \mathrm{~Hz}$ and a ramp rising from 1 to $1.25 \mathrm{~Hz}$. Similarly, the 1.0 -sec filter has a high cut at $1.3 \mathrm{~Hz}$ and a ramp rising from 0.6 to $0.7 \mathrm{~Hz}$. 
receiver response taken from Hong and Helmberger (1978). This synthesis was produced by assuming a $S H$ wave arriving at vertical incidence below a basin with a depth to diameter ratio of $1: 8$. The curvature of the basin amplifies the first multiple by about a factor of two.

The $R_{\beta}(t)$ was constructed by trial and error keeping the number of spikes to a minimum and using the basin response as a guide. Performing the convolution operation, we obtain the simulated AR6 which appears to match the AR6 observation in most of its significant features. A suggested interpretation of $R_{\beta}(t)$ is that the first arrival is a diffraction from the other side of the fault, followed by the direct arrival and first multiple. The timing between the first two pulses and the large down spike at $\delta t=0.56$ and $0.23 \mathrm{sec}$, respectively. Thus, we expect $R_{\beta}(t)$ to enhance signals with periods between 1 and $0.5 \mathrm{sec}$ or 1 to $2 \mathrm{~Hz}$, probably stronger toward the higher frequency. Scaling the travel times by the ratio of $\alpha$ to $\beta$, we predict enhancement for $P$ waves at 5 to $10 \mathrm{~Hz}$, especially near $10 \mathrm{~Hz}$.

The $P$ waves for AR6 could well show this effect but it is difficult to be definitive given the fact that AR6 is nodal. However, the main event does show a spectral

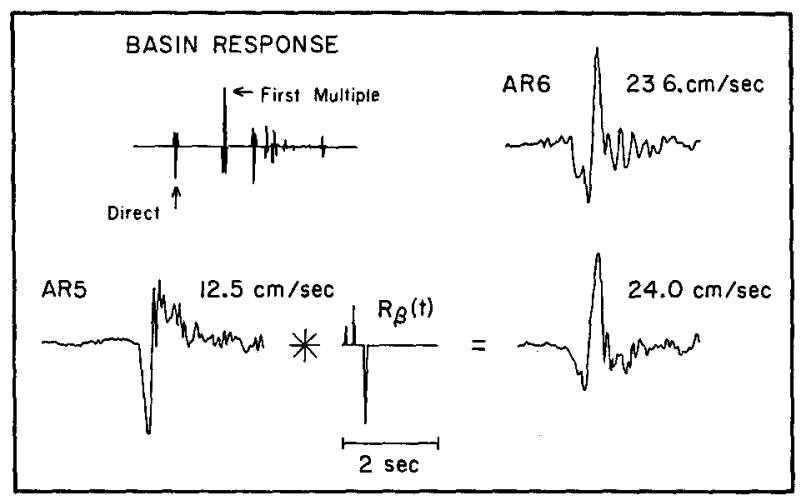

FIG. 13. Possible receiver function for shear waves, $R_{\beta}(t)$, constructed from three narrow triangles such that when convolved with AR5 one obtains a response similar to AR6.

enhancement of 7- to 12-Hz energy as is well known, see Mueller and Boore (1981), for example. Thus, given this collaborating evidence, we would suggest a basin structure roughly $500 \mathrm{~m}$ across and $50 \mathrm{~m}$ deep of soft sediments, probably with very low $Q_{\beta}$ values as well.

Experiments conducted on amplifications caused by three-dimensional structures (Rial, 1984, personal communication) indicate a great deal of variability depending on positions of all the foci. But, in general, we would expect slow arrivals to be focused and fast arrivals to be defocused (Scott and Helmberger, 1984). Thus, some of the scatter in Figure 12 can be explained by site effects which could be determined to some degree by geophysical means.

Returning to Figure 12 and comparing station AR5 and Bonds Corner (BOC), it appears that the ground accelerations at AR5 are larger than the average, whereas at BOC they are smaller. However, this difference is no longer seen at accelerations filtered at $1 \mathrm{sec}$. We interpret this as a directivity effect, where the source ruptured toward the north, and produced high-amplitude, high-frequency accelerations at station AR5 (northern station) and low-amplitude, longer-period accelerations at BOC (southern station) as discussed earlier.

Next, we address the question of radiation pattern and the frequency dependence 
of nodal stations. Generally, seismologists plot the amplitudes as a function of azimuth for strike-slip faults and observe a classical four-lobed pattern for longperiod signals. However, in this situation where receiver and directivity effects are prevalent, we need to modify this presentation slightly. It appears that dividing the tangential motion $(T)$ and radial motion $(R)$ by the rms is one way to suppress these complications, since the $S$ waves should be affected in roughly the same manner at each station. These normalized amplitude plots as a function of frequency are displayed in Figure 14 for the transverse and radial components, respectively. For higher frequency waves (the unfiltered accelerations), there does not appear to be much evidence for distinct nodes. However, for the filtered 1.0-sec accelerations, the nodes start to appear. This feature can be simulated by complex faulting where the geometries of the two sources have slightly different orientations, as the twosource radiation pattern indicated in Figure 7 , a and $b$.

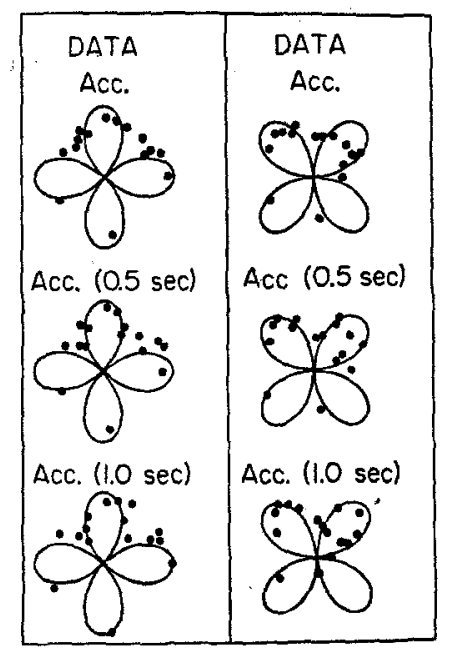

FIG. 14. The normalized amplitude plots for the ground accelerations in both transverse and radial components. These illustrate the radiation patterns from the recorded accelerations and filtered accelerations with passed bands near $0.5 \mathrm{sec}$ and 1.0 sec.

It would appear that simply adding a distribution of dislocations slightly rotated might explain the absence of observed nodes at high frequency. But, the strength of some of these strong accelerations at supposed nodes implies sharp jumps in fault dislocation. Hypothesis testing by a direct data inversion such as displayed in Figure 7 suggests that the data will accept severe complexity. This feature results even with very few free parameters. But, since this complexity consumes extra moment or the two events are opposing each other in a significant portion of the motion field, we must seriously wonder about the uniqueness of such a solution. On the other hand, the geology associated with this small portion of the fault could be complex. Most of the inversion studies on the main event obtain interesting behavior near this location. Hartzell and Helmberger (1982) suggest an asperity or high energy release at this location with a jog in the fault strike. Olson and Apsel (1982) obtain a sharp increase in their first episode of slip near this location (see their Figure 6). In light of such a situation, we can perhaps speculate on the possible meaning of our aftershock results. Since the stress drops are so high we could easily be seeing the rupture of fresh rock. Thus, the first event might be interpreted as a fresh rock in which a small portion of a possible asperity is broken followed by slip on the throughgoing fault. Juding from the stress drops implied by the short duration 
of this aftershock, we would suggest that a great deal of stress is still available in this region for future activity.

In conclusion, we found that one of the best-recorded aftershocks to date could be modeled reasonably well by assuming a complex rupture involving two sources; the first source (strike $=\mathrm{N} 319^{\circ} \mathrm{E}, \operatorname{dip}=42^{\circ} \mathrm{NE}$, and rake $=165^{\circ}$ ) has a moment of $0.7 \times 10^{24}$ dyne-cm and the second source (strike $=\mathrm{N} 324^{\circ} \mathrm{E}$, dip $=82^{\circ} \mathrm{SW}$, and rake $=181^{\circ}$ ) lies about $0.5 \mathrm{~km}$ to the north and has a seismic moment twice that of the first source. We obtained these source parameters by applying the amplitude inversion method with all the other parameters assumed. The advantage of this inversion method is the usage of the relative amplitude information which can provide better constraints on the source mechanism. However, there are many uncertain factors which can introduce noise in the amplitudes, among these, the source time function is the most important one. In this study, the source time function for each station is derived from a trial and error result.

The source parameters derived from horizontal strong motion velocities can also model the observed vertical velocities at least at the six available stations. This constrains the moment of longer period $P$ waves and quantifies the apparent attenuation difference for high-frequency waves. We suggest that a layered basin structure separates the $P$ waves from the $S$ waves onto vertical and horizontal components. The high-apparent attenuation for $S$ waves is responsible for producing low amplitudes and the longer period $S$ phases. The apparent $t_{\alpha}{ }^{*}$ of 0.001 and $t_{\beta}{ }^{*}$ of about 0.08 to 0.1 can explain this commonly observed feature for $P$ and $S$ waves seen in this sedimentary basin.

\section{ACKNOWLEDGMENTS}

We thank Steve Hartzell, Ronan Le Bras, and Gladys Engen for reviewing the manuscript and providing some helpful suggestions. We also thank Gerald Brady for providing the raw data used in this study. We acknowledge David Boore for his critical review and thank him for his excellent suggestions. This research was supported by the National Science Foundation, Grant CEE-812719.

\section{REFERENCES}

Anderson, D. L., A. Ben-Menahem, and C. B. Archambeau (1965). Attenuation of seismic energy in the upper mantle, J. Geophys. Res. 70, 1441-1448.

Boore, D. M. and J. B. Fletcher (1982). Preliminary study of selected aftershocks from digital acceleration and velocity recordings, U.S. Geol. Surv. Profess. Paper 1254.

Brady, A. G. and R. L. Porcella (1983). Imperial Valley aftershocks during the first 24 hours: a discussion of the strong-motion records (in press).

Carpenter, E. W. (1967). Teleseismic signals calculated for underground, underwater and atmospheric explosion, Geophysics 32, 17-32.

Fuis, G. S., W. D. Mooney, J. H. Healy, and G. A. McMechan, and W. J. Lutter (1981). Crustal structure of the Imperial Valley region, U.S. Geol. Surv. Profess. Paper 1254.

Hadley, D. M., D. V. Helmberger, and J. A. Orcutt (1982). Peak acceleration scaling studies, Bull. Seism. Soc. Am. 72, 959-979.

Hanks, T. C. and R. K. McGuire (1981). The character of high-frequency strong ground motion, Bull. Seism. Soc. Am. 71, 2071-2096.

Hartzell, S. T. and D. V. Helmberger (1982). Strong-motion modeling of the Imperial Valley earthquake of 1979, Bull. Seism. Soc. Am. 72, 571-596.

Helmberger, D. V. and D. G. Harkrider (1978). Modeling earthquakes with generalized ray theory, Proceedings of IUTAM Symposium: Modern Problems in Elastic Wave Propagation, John Wiley \& Sons, Inc., New York, 499-518.

Helmberger, D. V., G. Engen, and P. Scott (1979). A note on velocity, density and attenuation models for marine sediments, J. Geophys. Res. 84, 667-671.

Hong, T.- L. and D. V. Helmberger (1978). Glorified optics and wave propagation in nonplanar structure, Bull. Seism. Soc. Am. 68, 1313-1358.

Liu, H. L. and D. V. Helmberger (1981). An explanation for the high-frequency vertical strong motions recorded in sedimentary basins, EOS 61, 1036. 
Mellman, G. R. (1978). A method for waveform inversion of body-wave seismograms, Ph.D. Thesis, California Institute of Technology, Pasadena, California.

Molnar, P. J., B. E. Tucker, and J. Brune (1973). Corner frequency of $P$ and $S$ waves and models of earthquake source, Bull. Seism. Soc. Am. 63, 2091-2104.

Muller, C. S. and D. M. Boore (1981). Site amplification at El Centro strong ground motion array, station 6, Earthquake Notes 52, 84.

Olson, A. H. and R. J. Apsel (1982). Finite faults and inverse theory with applications to the 1979 Imperial Valley earthquake, Bull. Seism. Soc. Am. 72, 1969-2001.

Scott, P. and D. V. Helmberger (1984). Applications of the transmitted Kirchhoff-Holmholtz method to transmitted body waves and possible structural effects at NTS, Bull. Seism. Soc. Am. 75, 131-156.

Wallace, T., D. V. Helmberger, and G. Mellman (1981). A technique for the inversion of regional data in source parameter studies, J. Geophys. Res. 86, 1679-1685.

Seismological Laboratory (252-21)

California Institute of TeChNOLOGY

Pasadena, California 91125

Contribution No. 4062

Manuscript received 14 May 1984 


\section{APPENDIX: INVERSION METHOD}

In order to include the amplitude information in the inversion procedure, we define the error $e_{i}$ for each seismogram $i$ as

$$
e_{i}=\int_{o}^{T}\left[f_{i}(t)-g_{i}(t)\right]^{2} d t
$$

where $f_{i}(t)$ represents the observed data trace, $g_{i}(t)$ is the synthetic seismogram generated from starting model parameters, and $T$ is the time segment used in inversion procedure.

The inversion scheme is similar to the waveform inversion method of Mellman (1978), Wallace et al. (1981), and Le Bras (in preparation, 1984). The optimal solution is obtained by changing the model parameters which minimizes the sum of the square of the error function. This can be expressed as

$$
\varepsilon^{2}=\sum_{j=1}^{N} e_{j}^{2}
$$

where $N$ is the total available data traces. For an initial model $m_{0}$ and the corresponding error $e_{j}^{0}$, the model change $\delta m$, which minimizes the sum of the square error $\varepsilon^{02}$ can be written as

$$
\varepsilon_{j}^{02}(\delta m)=\left(e_{j}{ }^{0}+\delta e_{j}\right)\left(e_{j}{ }^{0}+\delta e_{j}\right)
$$

and

$$
\delta e_{j}=\frac{\partial e_{j}}{\partial \theta_{k}} \delta \theta_{k}
$$

where $\theta_{k}$ are the source parameters, including the seismic moment, strike, rake and dip for each source element.

Following (A3), the error functions and the partials can also be expressed in a matrix form as,

$$
\varepsilon^{2}(\delta m)=(e+A \varphi)^{T}(e+A \varphi)
$$

where $A$ is an $N \times M$ matrix with elements

$$
a_{i j}=\frac{\partial e_{i}}{\partial \theta_{j}},
$$

$M$ is the number of source parameters, and $\varphi$ is the matrix of the variation of source parameters, $\delta \theta_{k}$. Calculating the variation of $\delta \varphi$ and setting to zero, we have

$$
\varphi=\left(A^{T} A\right)^{-1} A^{T} e
$$

where -1 represents the generalized inverse and superscript $T$ denotes the transpose. Thus, the model variation $\varphi$ can be obtained from the partial matrix $A$ and the error function $e$. In order to stabilize the inversion scheme, an extra damping term 
is added, thus the final equation used for inversion is

$$
\varphi=\left(A^{T} A+\delta I\right)^{-1} A^{T} e
$$

where $\sigma$ is the damping coefficient and $I$ is the unit matrix.

In the following, a brief summary of expressing the synthetic seismograms in terms of the dislocation source model will be described. The displacements in cylindrical coordinate can be expressed as

$$
\begin{aligned}
& w(r, z, \theta, t)=\frac{M_{0}}{4 \pi \rho}\left(\dot{D}(t) * \sum_{i=1}^{3} W_{i}(t) A_{i}\right) \\
& q(r, z, \theta, t)=\frac{M_{0}}{4 \pi \rho}\left(\dot{D}(t) * \sum_{i=1}^{3} Q_{i}(t) A_{i}\right) \\
& v(r, z, \theta, t)=\frac{M_{0}}{4 \pi \rho}\left(\dot{D}(t) * \sum_{i=1}^{2} V_{i}(t) A_{i+3}\right)
\end{aligned}
$$

where $\dot{D}(t)$ is the source time function, $M_{0}$ is the seismic moment, and $W_{i}, Q_{i}$, and $V_{i}$ are the step responses for radial, vertical, and transverse components, respectively. The orientation constants $A_{i}$ are given by

$$
\begin{aligned}
& \left.A_{1}, \theta, \lambda, \delta\right)=\sin 2 \theta \cos \lambda \sin \delta+\frac{1}{2} \cos 2 \theta \sin \lambda \sin 2 \delta \\
& A_{2}(\theta, \lambda, \delta)=\cos \theta \cos \lambda \cos \delta-\sin \theta \sin \lambda \cos 2 \delta \\
& A_{3}(\theta, \lambda, \delta)=\frac{1}{2} \sin \lambda \sin 2 \delta \\
& A_{4}(\theta, \lambda, \delta)=\cos 2 \theta \cos \lambda \sin \delta-\frac{1}{2} \sin 2 \theta \sin \lambda \sin 2 \delta \\
& A_{5}(\theta, \lambda, \delta)=-\sin \theta \cos \lambda \cos \delta-\cos \theta \sin \lambda \cos 2 \delta
\end{aligned}
$$

where $\theta$ is the strike, $\lambda$ is the rake, and $\delta$ is the dip angle.

Several source elements or fault segments can be inverted simultaneously. Thus, the synthetic seismogram, $g_{i}(t)$ is simply the sum of the contribution from all the fault elements and can be expressed as

$$
g_{i}(t)=\sum_{j=1}^{L} d_{j} \bar{g}_{i j}(t)
$$

where $d_{j}$ is the scaling factor and is proportional to the moment of the source element $j$, and $\bar{g}_{i j}(t)$ is the unit moment contribution at station $i$ from source element $j$.

Combining equations (A1) and (A12), the error function $e_{i}$ then can be expressed as

$$
e_{i}=\int f_{i}{ }^{2}-\sum_{j=1}^{L} 2 d_{j} \int f_{i} \bar{g}_{i j}+\sum_{l=1}^{L} \sum_{j=1}^{L} d_{j} d_{l} \int \bar{g}_{i j} \bar{g}_{i l},
$$

where $\bar{g}_{i j}$ can be one of (A8), (A9), or (A10), which relate directly to the model parameters, $\theta_{j}, \delta_{j}$ and $\lambda_{j}$. Thus the partials can be obtained by taking derivatives with respect to $d_{j}, \theta_{j}, \delta_{j}$, and $\lambda_{j}$ in equation (A13). 